\section{A era da}

informação:

gênese de uma

denominação

descontrolada*

\section{RESUMO}

Neste artigo o professor Armand Mattelart faz uma análise dos trabalhos que serviram de degraus para consolidar 0 conceito contemporâneo de "era da informação" na Comunicação Social.

\section{ABSTRACT}

In this paper, Prof. Armand Mattelart analyses the main works which have supported the construction of the contemporary notion of "the information era" in communication studies.

\section{PALAVRAS-CHAVE/KEY-WORDS}

- Globalização (Globalization)

- Informação (Inform-ation studies)

- Teorias da comunicação (Communication theories)

\section{Armand Mattelart}

Professor Universidade de Paris VIII
"A história da humanidade é habitualmente descrita em termos de eras cujos nomes refletem as etapas de desenvolvimento pelas quais ela passou: a idade da pedra, a idade do bronze, a idade do ferro e assim por diante, de modo a chegar até a era industrial, que estabeleceu os fundamentos de nossa sociedade industrial moderna. Hoje em dia é cada vez mais admitido em geral que ingressamos em uma nova era, uma etapa pós-industrial, em que a capacidade de utilizar a informação se tornou decisiva, não apenas para a produção dos bens, mas também para os esforços que procuram melhorar a qualidade de vida. Essa nova era é cada vez mais denominada por todos de era da informação." (Publicidade da IBM, 1977)

A APARIÇÃO DA OBRA de Manuel Castells (1998), A Era da informação: economia, sociedade e cultura, fornece a ocasião para lembrar e, para alguns, de fazer circular trabalhos que serviram de degraus para a escalada da noção de "era da informação".

Seguindo os passos desse acontecimento editorial, reeditou-se em 1999, precedido de um prólogo inédito contendo 30 mil palavras, o livro de Daniel Bell, O Advento da Sociedade Pós-Industrial [The comming of a PostIndustrial Society], cuja edição original remontava a 1973 e, a segunda, a 1976.

Na capa havia uma frase escrita pelo sociólogo espanhol: "One of the great seminal works of the last half century and also ... the next century". No prólogo, Bell saúda 
A Era da informação como "the most ambitious effort to redraw the map of society" $\mathrm{e}$ sublinha que seu autor está "making obseisance to the early work of myself and Alain Touraine" (1999: 23). Os quatro testemunhos que figuram lado a lado na capa corroboram o sentimento do sociólogo americano. Manifestam seu apoio com destaque o Prêmio Nobel de Economia, Kenneth J. Arrow, e Joseph S. Nye, deão da Escola de Governo Kennedy, da Universidade de Harvard, conhecido por sua teoria do soft power na era das redes. Bell inicia seu prólogo mostrando índices com os quais supõe provar que seu conceito de sociedade pós-industrial passou a fazer parte do patrimônio lingüístico: trata-se de um sumário efetuado a partir do banco de dados Nexus, de 104 citações da expressão em artigos ou discursos publicados entre agosto de 1997 e 1998; de um desfile de célebres usuários do termo, desde Bill Clinton e Vaclav Havel até Margaret Tatcher e sir Leon Brittain, comissário europeu e negociador junto ao Gatt, quando dos debates sobre a excepcionalidade da produção de cultura, passando pelo senhor Kaczynski, aliás, Unabomber. A vontade de fundar o caráter antecipador da noção de "sociedade de informação" ao mesmo tempo que sua pertinência intelectual, vinte e cinco anos depois de sua "invenção", predomina em um prólogo que tudo leva a entender como uma espécie de "lifting" da noção de sociedade pós-industrial para a era da globalização e da Internet. Existe aí bem a questão das "trajetórias" tecnológicas, mas também um ponto de retorno sobre a trajetória de um projeto intelectual.

Nosso propósito é voltarmo-nos sobre a configuração política e ideológica que confere sentido ao $O$ Advento da Sociedade Pós-Industrial nos anos 60 e 70, a fim de lhe restituir a relação com outros cenários sobre o futuro da sociedade tecnológica que então estavam aparecendo nessa época, particularmente rica em neologismos. Essa arqueologia das representações é também para nós uma ocasião de retomar análises anteriores, de reenquadrá-las e de as prolongar (Mattelart \& Mattelart 1986; Mattelart, 1992, 1996).

\section{Um debate sociológico}

\section{O fim das ideologias}

Duas controvérsias preparam o advento da noção de "sociedade pós-industrial". A primeira trazia à discussão a "sociedade de massa". A segunda referia-se à clivagem entre capitalismo e comunismo.

“Uma das expressões favoritas de nosso tempo - nota Daniel Bell em 1963 - é a de sociedade de massa, empregada tanto para exprimir o aspecto passivo da existência e sua mecanização quanto a desaparição dos critérios de julgamento. Esses diferentes empregos da palavra refletem as filosofias reacionárias ou progressistas, porque a expressão, aparentemente apenas descritiva, em realidade é plena em toda uma série de julgamentos sobre a sociedade moderna" (Bell, 1963: 1). Trata-se de um debate tão velho quanto a própria sociedade industrial. Não se encontra seus traços já em Alexis de Tocqueville e Thomas Carlyle? Trata-se de um debate igualmente tão antigo quanto a própria sociologia, porque é constitutivo de seu nascimento. Desde o fim da Segunda Guerra Mundial, a controvérsia foi relançada pela crítica da Escola de Frankfurt à função massificadora da indústria cultural, as análises de David Riesman sobre a multidão solitária ou, ainda, os ensaios de Hannah Arendt sobre a "crise de nosso tempo". A revista Communications, onde Bell publica o artigo do qual a citação é extraída, toma a seu encargo essa discussão porque ela é órgão do Centro de Estudos sobre as Comunicações de Massa (CECMAS), que acaba de fundar Roland Barthes, Edgar Morin e Georges Friedmann no quadro da Escola Prática de Altos Estudos. A polêmica sobre os "efeitos da cultura de massa", que põe frente a frente duas concepções da democracia, divide os intelectu- 
ais de todas as latitudes de acordo com a divisão entres apocalípticos e integrados (Eco, 1964). Bell contesta os segundos, críticos da cultura midiática como dispositivo de poder, por reduzirem o debate nos termos do "tudo ou nada".

Tais são os "julgamentos emitidos sobre a sociedade moderna" e mais centralmente emitidos pelas "filosofias progressistas", em que o sociólogo estava no encalço em 1960, quando escrevera O Fim da ideologia (1960). Nessa obra ele tenta superar a noção de sociedade de massa determinando as novas condições de efetivação das democracias industriais contemporâneas. Democracias que, segundo ele, se caracterizam pelo "fim da ideologia". Pelo fim das classes, dos confrontos radicais, das velhas paixões políticas e pelo desaparecimento dos intelectuais contestadores. Esse discurso sobre o fim é então um ponto de encontro de numerosos "politólogos" e sociólogos, sobretudo americanos. O tema foi adubado cinco anos mais tarde em nível internacional, quando do Congresso pela Liberdade da Cultura, organizado em Milão e no qual estiveram presentes Colin Clark, Friedrich von Hayek, Raymond Aron, Seymour Lipset, Edward Shills e o próprio Bell. Os participantes debateram a emancipação do pensamento liberal e socialista diante da perspectiva de sua eventual convergência em prol de uma "sociedade livre". Bell jamais fez mistério dessa conivência: "Um certo número de sociólogos Aron, Shils, Lipset e eu mesmo - foi levado a ver os cinqüenta como os anos do 'fim das ideologias'" (Bell, 1976: 41). Bell repetirá em várias ocasiões sua dívida para com as lições de Aron sobre a "sociedade industrial" (Aron, 1955). Raymond Aron (19051983) é uma das raras figuras da sociologia francesa presentes em Milão. Acabara de publicar, em 1955, O Ópio dos intelectuais, onde denuncia a cegueira dos intelectuais engajados no novo milenarismo que encarnava, segundo ele, a ideologia comunista (Aron, 1962). Na tribuna, reiterava sua convicção íntima sobre o declínio das fontes do grande conflito ideológico que caracterizou a primeira metade do século $X X$, ao mesmo tempo em que repetia sua fé em um socialismo e em um liberalismo renovados mas "sem engajamento".

O Congresso de Milão que tinha por tema "O futuro da liberdade" constitui, pois, um momento decisivo na cristalização da tese do fim das ideologias. O mundo universitário anglo-saxão estava então na vanguarda das redes que propagariam as teses neoliberais. Em 1944, Friedrich von Hayek (1899-1992), professor da London School of Economics e futuro Prêmio Nobel de Economia, lançou a carga contra o coletivismo publicando O Caminho da Servidão (The Road to Serfdom). No ano seguinte, o epistemólogo e filósofo inglês de origem austríaca Karl Popper (1902-1994) fazia aparecer A Sociedade aberta e seus inimigos. Essa defesa da sociedade aberta, capaz de liberar as capacidades criticas do indivíduo, alfineta as sociedades totalitárias contemporâneas, chamando-as de sociedades fechadas ou tribais que se encontram submetidas a formas maquinais. Popper faz remontar suas origens ao programa político elitista dos "filósofos-reis" de Platão e aos modelos proféticos de Hegel e de Marx, que ele acusa de historicismo, por terem erigido em dogma as supostas leis gerais do desenvolvimento histórico que fariam previsível o curso dos acontecimentos e se diziam capazes de determinar a totalidade da sociedade do futuro. Contra toda "tecnologia social utópica", Popper defende um reformismo liberal conforme a tradição anglo-saxônica (1950). Hayek e ele conheceram-se em 1936. Popper chegou a expor sua crítica do historicismo no contexto de um seminário de Hayek em 1937, e não deixará de fornecer um apoio constante, embora crítico, a seu entendimento neoliberal. A vitória do partido trabalhista em 1945 e o temor de ver o intervencionismo keynesiano readquirir força na Grã-Bretanha incitaram o economista a se converter em ativista da causa neoliberal. Junto com um punhado de economistas de direita ele 
lança em 1947 um primeiro centro de reflexões ou think tank (a "Sociedade do MontePèlerin", Suíça) com o objetivo explícito de construir uma alternativa política ao reformismo socialista. Cabeça de ponta do pensamento neoliberal, a rede que ele estabelecera progressivamente, sobretudo nos países anglo-saxões (e, com o tempo, latinoamericanos), assume sua real dimensão internacional quando ele passa a fazer parte da Universidade de Chicago, onde se tornará colega do inventor do monetarismo, Milton Friedmann, outro futuro Prêmio Nobel e futuro mestre-pensador dos Chicago Boys chilenos que transformaram o regime ditatorial do general Pinochet em espécie de laboratório natural da nova economia liberal.

\section{Rumo à sociedade gerencial}

O conceito de ideologia sob o qual se abrigavam os participantes do Congresso de Milão nada tinha a ver com o que Roland Barthes utiliza nas crônicas que ele reúne em suas Mitologias (1957) e que será reabilitado pelo conjunto do movimento estrutural dos anos 60. Corresponde à definição que então prevalece das ciências sociais do estabelecimento funcionalista anglo-saxão: “Um modelo de crença e de conceitos (ao mesmo tempo factual e normativo) que visa a explicar aos indivíduos e grupos sociais um fenômeno complexo a fim de canalizar e simplificar sua escolha" (Gould \& Kolb, 1964: 315). Visto como coisa do adversário, o conceito é sistematicamente conjugado com os termos "fanatismo", "dogmatismo", "doutrinarismo", "fantasia obsessiva", senão "possessão". Na resenha sobre os debates da sociologia da cultura de massa, que Edward Shills escreve para a revista Encounter sob o título "The End of Ideology ?", recorre-se a todas essas expressões que conotam um estado de catarse emocional (Shills, 1955). Inclusive se para quem a formula, a resposta não tem mais dúvida depois de tanto tempo, trata- se da primeira vez que a pergunta é abertamente colocada. De todo modo é nesse contexto que aparecem cinco anos mais tarde não apenas a obra O Fim da ideologia, de Daniel Bell, mas uma outra, Political Man, de Seymour Martin Lipset (Bell, 1960; Lipset, 1960). Tomando-o de empréstimo a Shills, a quem presta homenagem, o título por ele dado ao último capítulo de sua obra é "The End of Ideology". Nele ele passa em revista as trocas de impressões que teve em Milão. Apoiadas pelos indicadores socioeconômicos, essas obras proclamam a vitória da "análise sociológica" sobre a "ideologia" e certificam o desaparecimento das "intensidades dos conflitos políticos" nas grandes democracias ocidentais doravante estabilizadas e, portanto, da "luta de classes" e, com ela, o anacronismo dos slogans, das manifestações de rua e das "bandeiras vermelhas". Também é atestada a nova legitimidade da figura do "intelectual liberal ocidental". Nas poucas páginas dedicadas por Lipset às chamadas nações subdesenvolvidas, emana uma teoria da difusão universal da democracia por meios de comunicação afinados com os pressupostos da teoria da modernização/westernalization.

Outra tese recorrente e possuidora de autoridade à época do Congresso pela Liberdade da Cultura: a ascensão irresistível dos organization men e da Managerial Society. Essa tese seria pioneira apenas se o fosse, porque tendo precedido à do fim das ideologias, constitui de certo modo sua primeira sedimentação. Ainda que encontremos seus germes em Veblen e Schumpeter, observadores atentos da escalada da força dos especialistas, essa tese foi formalizada por James Burnham, professor de filosofia da Universidade de Nova York, em um livro redigido em 1940, e que, publicado em 1941, produziu sensação nos Estados Unidos: The Managerial Revolution. Diante da dificuldade de encontrar um equivalente para managerial e management, o editor da tradução francesa, publicada em 1947 em uma coleção dirigida por Raymond Aron intitulada "Liberté Del 'Esprit", verterá o 
título como "L'ére des organisateurs" e, no texto, Managerial Society se converterá em "Societé directorale".

Para Burnham, essa obra significa em primeiro lugar um ato de ruptura com o trotskismo e a IV Internacional, após uma polêmica particularmente exacerbada com o próprio Trotsky sobre a natureza do marxismo e do socialismo. A "Revolução gerencial", postula o autor, está em via de tornar obsoleta a divisão capitalismo/socialismo. Dentro de um prazo que ele estima curto (um meio século no máximo), o regime capitalista, sua ideologia liberal, a divisão da sociedade segundo esquema proprietários/proletários, a apropriação privada dos instrumentos de produção, tudo isso será deixado para trás por uma revolução pacífica e silenciosa que conduzirá ao poder uma "nova classe social", com sua própria consciência de classe, seus interesses e seus privilégios: os "gerentes". Trata-se dos administradores que, de fato, já comandam os meios de produção. A mesma tendência está em curso na União Soviética, onde a liquidação do capitalismo enseja o aparecimento de uma camada de tecnocratas. Nos dois sistemas, emerge um "regime gerencial" que rompe com a maneira tradicional de conceber o político. Contrariamente ao que previa Marx, o declínio do regime capitalista não deverá, pois, levar necessariamente ao advento do socialismo. A Primeira Guerra Mundial foi também o último conflito capitalista e o primeiro entre "gerentes"! A Segunda Guerra Mundial é um confronto típico entre "sociedades gerencias".

\section{Uma comunidade carismática sem ideologia}

Durante os anos 60 o "fim das ideologias" e a "era dos organizadores" se entrelaçaram com o tema do advento da "sociedade industrial". Daniel Bell confessa que usou essa expressão pela primeira vez em suas contribuições ao seminário de Salzburg, ainda que não a tenha formalizado senão três anos mais tarde, em um trabalho intitu- lado "The Measurement of Knowledge", apresentado durante um fórum sobre tecnologia e a mudança social organizado em Boston (Bell, 1968a). Trata-se de fato de uma contribuição à "teoria dos indicadores de mudança social". Ela indica que a geração pré-industrial privilegia uma demanda lógica em vez da heurística, procura métodos ditos objetivos e técnicas quantitativas.

Quando Bell lança O Advento da Sociedade Pós-Industrial, em 1973, ele situa o livro em relação ao precedente: "O ponto de partida de O Fim da Ideologia era implícito: o papel que a tomada de decisão técnica havia assumido na sociedade. Ora, essa pode ser interpretada como diametralmente oposta à ideologia: enquanto uma é calculadora e instrumental, a outra releva da emoção e da força expressiva ... O tema daquele livro era o enfraquecimento das antigas paixões políticas. Os temas que desenvolvo em $O$ Advento da Sociedade Industrial procuram explorar o pensamento tecnológico e seus laços com a política" (1973: 34). O interesse do sociólogo americano pelas novas elites técnicas e a tecnocracia remonta aos anos 50. Sua contribuição ao Congresso de Milão já tratava da transição do capitalismo familiar para o capitalismo gerencial.

Preferindo chamar pós-industrial à nova sociedade, Bell coloca a distância outras denominações que circulavam, notadamente a expressão "sociedade pós-capitalista", forjada por Rolf Dahrendorf em 1959, ou o termo "sociedade ativa", lançada dez anos mais tarde por Amitaï Etzioni. A expressão "pós-industrial" parece-lhe mais apta para significar, por um lado, que vivemos em um "tempo intersticial", porque as novas formas sociais não se destacam ainda muito claramente; e, de outro, que as origens dessas mutações são antes de tudo fatos "científicos e tecnológicos". Mesmo se os recusa no prefácio da edição de 1976, o autor não teme em usar os rótulos "sociedade do conhecimento" ou "sociedade da informação". Por conhecimento (savoir) ele entende um "conjunto organizado de afirmações, de fatos ou de idéias, que apresen- 
ta um raciocínio ou um resultado experimental passível de transmissão a outros através de meios de comunicação sob uma forma sistemática". A informação engloba a "estocagem, a transmissão e o tratamento dos dados enquanto base de todas as trocas econômicas e sociais" e se distribui em três categorias: o registro (notas fiscais, seguros sociais, operações bancárias, créditos, etc.); os programas (reservas de passagens aéreas, planos de produção, elaboração de inventários, etc.); as bibliotecas e a demografia (recenseamentos, pesquisas de opinião, estudos de mercados, boletins eleitorais, etc.).

O subtítulo de $O$ Advento da Sociedade Pós-industrial esclarece o empreendimento de Bell: Tentativa de previsão sociológica. Trata-se de uma "previsão social". A partir das "tendências estruturais" (trends) observáveis nos Estados Unidos, o sociólogo põe em cena uma sociedade futura "típicoideal", cuja mutação compreenderia cinco dimensões:

1.o deslocamento do principal componente econômico (passagem de uma economia de produção para uma economia de serviço);

2.o deslizamento na estrutura de emprego (proeminência dos técnicos e profissionais);

3.a nova centralidade adquirida pelo saber teórico como fonte de inovação e de formulação das políticas públicas;

4.a necessidade de balizar o futuro por antecipação;

5.a promoção de uma nova "tecnologia intelectual" voltada para a tomada de decisões.

Inédito e decisivo na sociedade industrial é a expansão dos "serviços humanos" (saúde, educação e serviços sociais) e dos "serviços técnicos e profissionais" (pesquisa, avaliação, tratamento informático e análise de sistemas). Aparece um esquema distinto daquele sugerido pela tipologia do economista Colin Clarck, que repartia as atividades econômicas em setores primá- rio, secundário e terciário, serviços pessoais (entrevistas, revistas, garagens, lavanderias, etc.), serviços comerciais (bancos e financeiras, companhias de seguros, imobiliárias) ou de transporte (Clark, 1940). A taxa de crescimento dos profissionais e técnicos representa o dobro da média em que cresce o conjunto da força de trabalho. O crescimento dos cientistas e engenheiros representa o triplo. Forma-se assim uma nova inteligência, que tem seu nicho nas "universidades, nas instituições de pesquisa, nas profissões e nos governos". Do ponto de vista da estratificação e do grau de poder, a figura dominante da sociedade industrial era o homem de negócios e o espaço social principal a empresa. Na sociedade pós-industrial, essa centralidade passa a pertencer aos cientistas e pesquisadores, às universidades e centros de pesquisa. Dado que a ocupação define a classe, passa a ser essa categoria social que codifica e testa o saber teórico, princípio axial da sociedade pós-industrial. Iluminando os mais variados campos de experiência, os sistemas abstratos de símbolos que esse grupo elabora selam a sobra do empirismo. Embora a sociedade pré-industrial fosse um "jogo contra a natureza", a industrial, um "jogo contra a "natureza fabricada", a sociedade pós-industrial é um "jogo entre as pessoas". A organização do mundo científico e de uma equipe de pesquisa em particular é a sua imagem, na medida em que simboliza a cooperação e a reciprocidade, ao invés da hierarquia e da coordenação.

A "comunidade científica" extrai sua legitimidade de sua natureza carismática. Universalista e desinteressada, essa "comunidade carismática" "não tem ideologia, no sentido que não postula um conjunto de crenças formais, mas possui um ethos que, implicitamente, prescreve-lhe regras de conduta. Está mais próxima do ideal da pólis grega, uma república de homens e mulheres livres, unida pela procura comum da verdade" (Bell, 1973: 380). A vitalidade desse ethos permite à comunidade científica se defender contra a burocratização, o 
assujeitamento político e o totalitarismo. A ciência é uma vocação. "Seu aspecto carismático confere-lhe essa qualidade 'sagrada' como condição do modo de vida de seus integrantes. Como a Cristandade, essa dimensão carismática faz com que ela tenha seu charme (ou atrativo) em uma utopia recorrente e talvez messiânica. Essa tensão entre esses elementos carismáticos e a realidade da organização é o que configurará as realidades políticas da ciência em uma sociedade pós-industrial." (Bell, 1973: 408) O sociólogo coloca nesse ponto a idéia de desmaterialização do trabalho na economia pós-industrial, segundo a qual, agora que a codificação do saber passa a imprimir sua dinâmica à inovação, a nova sociedade pode ser caracterizada não mais pelo labor theory of value mas pela knowledge theory of value!

Programação linear, simulação, teoria da informação, cibernética, teorias da decisão, teorias dos jogos, teoria da utilidade: todas essas novas "tecnologias intelectuais" procedem à substituição dos julgamentos intuitivos pelo algoritmo. Ajudando a definir a ação racional e a identificar os meios para chegar a ela, elas oferecem a possibilidade de gerar a "complexidade organizada" (complexidades macrossistêmicas e organizacionais, complexidade da teoria que manipula com número crescente de variáveis). Vale o mesmo para a "complexidade desorganizada", porque a teoria das probabilidades fez muitos progressos em relação ao "problema do homem médio".

Monitoring the social change e, com esse fim, criar os mecanismos para antecipar o futuro - tal é a senha para ingressar na era pós-industrial. Graças às novas técnicas de previsão, torna-se factível reduzir a margem de indeterminação do futuro econômico. Os métodos de technology assessment estão aí para contribuir com a regulação do crescimento das novas tecnologias. O governo dos Estados Unidos não se dotou de um Technology Assessment Office, depois que uma lei para tanto foi votada em 1967? Somente a planificação e o controle da tecnologia através dos mecanismos de regula- ção política estão em condições de se contrapor à market economy, influenciada pelas eventualidades das vontades privadas e fazer respeitar as "necessidades comuns" das quais se encarrega a "economia pública". O "setor público", ainda chamado de household público (em oposição a domestic household), que constitui um terceiro setor em relação à economia mercantil e à economia associativa. Trata-se de o que Bell exprimiu se referindo à questão, primordial para a sociedade pós-industrial, dos conflitos entre o econimizing mode, dominado pela eficácia funcional e a gestão das coisas e dos homens administráveis como tais, e o sociologizing mode, através do qual a consideração dos valores não-econômicos implica necessariamente a perda de eficácia e redução da produção. Diante dessa divergência entre "custos privados" da empresa e "custos sociais" (as externalidades, na língua dos economistas), o único árbitro possível é o princípio de responsabilidade social.

\section{Uma história linear}

Devemos observar o que sobre o tipo-ideal "sociedade pós-industrial"? Em primeiro lugar, ruptura que ela significa em relação à primeira geração do pensamento pós-industrial e seu modelo de sociedade futura. Inaugurado no final do século XIX pelo anarquista Piotr Kropotkin e prolongado pelo socialista inglês Arthur J. Penny, esse pensamento contestatário defendia a democracia descentralizada e punha radicalmente em questão a lógica produtivista da sociedade industrial, valorizando a heterogeneidade e as diferenças, a desurbanização e o desenvolvimento harmonioso de todo o território, a reconciliação entre o cérebro e a mão, a unidade entre trabalho e recreação e o fim da dicotomia entre trabalho e lazer (Mattelart, 1999). O pós-industrialismo se transforma a partir de então em tema da moda nos corredores do poder.

Em seguida, verifica-se sua ancoragem na longa história das doutrinas organi- 
zacionais, no curso da qual se construiu o paradigma da "sociedade funcional" do qual a era pós-industrial deveria marcar o acabamento. Bell coloca três pessoas que conduziram a sociedade para a tecno-estrutura em seu panteão: Claude-Henri e SaintSimon, batizado o "pai da tecnocracia"; Frederic Winslow Taylor, o inventor do gerenciamento científico; Robert McNamata, antigo quadro da Ford e artesão da revolução logística do Pentágono nos anos 60, a qual, nota o autor, não teria sido possível sem o salto gigantesco dado pelos especialistas em organização durante a II Guerra Mundial.

Precisamos notar que a visão de história subjacente à noção de sociedade pósindustrial é linear; ela se conserva fiel ao esquema conforme o qual há uma maturação histórica da história - modernidadeprogresso ou, como diria Fernand Braudel, a concepção da história em fatias. O horizonte que se coloca e o da teoria matemática da informação. Prisioneira da ideologia do crescimento, que de resto seria exponencial, ela se desenvolve segundo um modelo de evolução aparentado ao que foi desenhado em 1960 pelo economista Walt W. Rostow em seu "Manifesto não-comunista" sobre a "etapas do crescimento econômico" (sociedade tradicional/ sociedade de transição/ sociedade decolante/ sociedade economicamente madura/ sociedade de consumo de massas) (1960). Todas são etapas canônicas do progresso dos níveis de vida e da riqueza que se supõe reproduzir universalmente e conduzir inevitavelmente a uma sociedade pós-industrial cujo arquétipo seriam os Estados Unidos. Esse esquema histórico é perfeitamente coerente com outro, derivado da teoria da informação, que como ele se tornou senso comum à época: a teoria da difusão de inovações. Os fluxos de inovações, da mudança social, partem de cima para baixo, dos emissores centrais e das elites técnicas para os administrados, das sociedades que atingiram uma etapa superior segundo o modelo "modernização/desenvolvimento" para as sociedade situadas nos escalões inferiores.

Enfim, chegamos à obliteração do pensamento da rede. A idéia de irradiação do centro para a periferia se conjuga em todos os níveis hierárquicos. Bell crê sobretudo na missão do Estado-providência que, em sua tarefa planificadora, também é uma estrutura centralizada. Ele se mostra reticente diante da "democracia participativa", tema e reivindicação que circulavam a sua volta nos final dos anos sessenta nos Estados Unidos e do qual podemos encontrar testemunho na tese comunitarista da nova "sociedade ativa" acionada por cabo (Etzioni, 1968).

\section{A sociedade programada}

Do passado como simpatizante do movimento trotskista, Daniel Bell conserva uma grande erudição dos clássicos do marxismo, ainda que Marx lhe sirva sobretudo de repositório para melhor fazer notar a pertinência contemporânea das análises de Max Weber. De sua passagem pelo marxismo, ele guarda sobretudo um ressentimento pronunciado. Ele contesta tudo o que o margeia pela esquerda, mesmo correndo o risco de desfazer amálgamas peremptórios, como o seguinte: "O tema da sociedade pós-industrial apareceu nos escritos de um certo número de teóricos europeus neomarxistas como Radovan Richta, Serge Mallet, André Gorz, Alain Touraine e Roger garaudy ... (mas) embora todos eles sentissem a urgência das mudanças estruturais na sociedade seus debates sobre a 'velha' e a 'nova' classe operária tomaram um acento tediosamente teológico" (Bell, 1973: 39). Resumidamente, para ele, todos esse autores procuravam "salvar" o "conceito marxista de mudança social" e "a idéia de ator da mudança". A tomada de partido é inegável porque, diversamente de seus colegas norte-americanos, Bell revela-se um conhecedor do que estava acontecendo na cena sociológica francesa e, mais particularmente, nos primeiros deba- 
tes sobre a tecnocracia, pois que dela extraiu a definição do termo e conhecia bem os trabalhos do sociólogo do trabalho Georges Friedmann. Além da breve alusão acima, não há nenhuma outra menção ao trabalho de Alain Touraine, que publica, em 1969, A Sociedade pós-industrial. Estamos bem longe do olhar clínico que, no prólogo de 1999, o sociólogo americano lançara a seu colega francês!

Quanto a Alain Touraine, notemos que não se gaba da expressão "sociedade pós-industrial". Embora intitule sua obra, ele prefere a expressão "sociedade programada" para designar as "sociedades de um novo tipo que se formam diante dos nossos olhos": "Chamaremo-nas sociedades pósindustriais se quisermos marcar a distância que as separam das sociedades industriais que lhes precederam e que ainda se confundem com elas, quer devido à forma capitalista, quer devido à forma socialista. Chamaremo-nas de sociedades tecnocráticas se quisermos nomear o poder que as domina. Chamaremo-nas sociedades programadas se buscarmos lhes definir a natureza de seu modo de produção e de organização econômica. Esse último termo me parece o mais útil porque indica mais diretamente a natureza do seu trabalho e da sua ação econômica" (Touraine, 1969: 7). De fato, apenas a extensa apresentação, que coordena os quatro capítulos, em grande parte extraídos de artigos isolados, publicados entre 1959 e 1968, refere-se ao primeiro termo.

Qual é a natureza dos conflitos em uma sociedade onde as novas formas de dominação social extravasam o quadro da oposição capital/trabalho e onde as lutas contra a exploração econômica e, portanto, a classe operária, deixam de ter a centralidade que possuíam na sociedade industrial? Uma sociedade onde a ação do poder tende a se tornar global, mais difusa e menos abertamente autoritária, buscando reduzir o conflito social através de uma "participação dependente" daqueles submetidos aos aparelhos de decisão econômica e política. Como nessa "sociedade alienada que seduz, manipula e integra" a "contestação criadora" pode se exprimir contra a mudança programada? Em Touraine, a análise das mutações do "jogo social" e das interações de seus atores ocupa o lugar das subversões tecnológicas e científicas em que Bell vê a origem da sociedade pós-industrial. Classes sociais antigas e novas, movimentos estudantis, racionalização das empresas e ligações entre trabalho, lazer e sociedade são sucessivamente analisados em quatro capítulos. Em comparação com a visão da sociedade pós-industrial de Bell, o capítulo sobre os movimentos estudantis é, segundo nosso modo de ver, o mais loquaz. Escrito durante a escalada da crise política e social desencadeada pelos acontecimentos de maio de 68 , oferece uma imagem da universidade singularmente distinta com relação à de seu colega americano. A universidade não é nela um santuário da comunidade carismática, mas o berço de um movimento social antitecnocrático.

Quanto ao último capítulo, concernente aos lazeres e originalmente publicado na revista Esprit em 1959, testemunha a precocidade da posição do sociólogo da ação diante das críticas à mídia e à cultura de massa "que não fazem senão defender uma concepção aristocrática da sociedade e reforçam um modo hierarquizado de consumo" (Touraine, 1969: 305).

\section{Uma questão de especialistas}

A explosão dos cenários

Embora não forneça o argumento de seu livro, a noção de sociedade pós-industrial foi desenvolvida por Bell no quadro da Comissão sobre o Ano 2000 da qual era presidente. Reunião por iniciativa da Academia Americana de Artes e Ciências 1965, essa comissão patrocinou a publicação de um relatório final em quatro volume por ele dirigido (Bell, 1968b). Esse documento ilustra o quanto estavam em voga as abordagens interessadas em fazer previsões e lança luz 
sobre os avatares do monitoring da mudança social.

Desde o final da II Guerra Mundial, os think tanks passaram a se interessar pela prospecção do futuro. Desde os anos 50, a Rand Corporation, uma das maiores fabricas de idéias, fundada com o apoio da aeronáutica americana em 1946, empregava uma técnica de previsão batizada de Delphi, inspirada nas pesquisas de opinião, que legitimava a idéia de que existem métodos objetivos para explorar o futuro. Seu procedimento consistia, num primeiro momento, em solicitar a um conjunto de especialistas uma previsão sobre uma questão precisa. Em seguida, as respostas (sempre anônimas e por correio) eram enviadas aos mesmos especialistas que, confrontados com as avaliações de seus colegas, negavam ou confirmavam as previsões anteriores. Observe-se o fato muito significativo de que o primeiro contrato que a Rand havia obtido envolvia a força aérea americana, constava de um estudo prospectivo sobre os satélites e a exploração espacial e exibia o título muito eloqüente de Preliminary Design of na Experimental World - Circling Spaceship. Esse interesse pela elaboração de cenários a respeito dos sistemas de comunicação e de informação, seja para uso civil ou militar, jamais será contestado. No final dos anos 60, a Rand se tornou um centro importante de produção de cenários sobre a "cidade cabeada" (wired city), campo de teste do discurso sobre as virtudes da rede e da interação.

O final dessa década e o período seguinte podem ser vistos como uma época gloriosa. As técnicas deram um salto: extrapolação de tendências (trends), métodos gráficos (relevance tree method), estudos de difusão temporal de tecnologias (diffusion times), pesquisa morfológica, etc. A previsão tecnológica (technological forecasting) se beneficia diretamente dos trabalhos realizados no quadro do Air Force Systems Command. As associações e as redes de especialistas imperam. Em 1966 funda-se em Washington a World Futures Society. Em 1968, o Institut for the Future. Em 1971, o primeiro contabiliza cerca de seis mil membros em 45 países. Conferências então se debruçam sobre a matéria: em Oslo (1967), em Kioto (1970). Revistas são lançadas com nomes como The Futurist, Futures, Technological Forecasting.

A futurologia descobre também os oráculos para uso de empresas e governos ávidos de conselhos e prontos a pagar por cenários, lançando mão de um viés através do qual o grande publico é chamado a se integrar às novidades do universo tecnossocial. O profissional mais emblemático desse ramo é, sem dúvida, Herman Kahn, antigo quadro da Rand Corporation e cofundador do Instituto Hudson. Depois de haver publicado diversos cenários sobre a escalada militar e a guerra termonuclear, redige, a pedido de Daniel Bell, o segundo volume do relatório final do supra-referido Congresso. Trata-se de um texto retomado em seu trabalho clássico O Ano 2000, publicado em 1967 em colaboração com Anthony Wiener e prefaciado por Bell. Kahn desenha a topografia das diversas sociedades no limiar do terceiro milênio, tomando como pano de fundo a idéia de pós-industrialização. Então o mundo se encontra dividido em cinco esferas, de acordo com a renda per capita: há o mundo pré-industrial (50 a 200\$), o parcialmente industrial (200 a 600\$), o industrial (600 a 1500\$), o industrial avançado ou de consumo de massas (1500 a 4000\$) e o pós-industrial (4000 a 20000\$). O painel, assim traçado, apresenta um mundo composto por vinte e um países pós-industriais: doze "visivelmente pós-industriais" (Estados Unidos, Canadá, Escandinávia, Suíça, França, Alemanha e Benelux) e nove apenas "parcialmente" (União Soviética, Tchecoslováquia, Reino Unido, Itália, Israel e Austrália, entre outros). A Argentina se encontra entre os países "industrialmente avançados", estando na mesma situação da Espanha, Venezuela, Grécia, Cingapura, Hong-Kong, Taiwan e as Coréias. O Chile se encontra no estágio industrial junto com México, África 
do Sul, Cuba, Líbia, Peru e Turquia. Quanto ao Brasil, está relegado à categoria de país "parcialmente industrializado", ao lado da China, da Índia, Paquistão e Egito.

Como sinal dos novos tempos, na "cibernetização" americana, matriz da sociedade pós-industrial e pós-escassez (post-scarcity), as pessoas não trabalham mais que 5 a 7 horas diárias, 4 vezes por semana e 39 semanas ao ano. Além dos 13 dias de férias legais, gozam de 13 semanas de descanso.

Diversos outros relatórios setoriais da Comissão sobre o Ano 200 cometerão a imprudência de conferir crédito demasiado à futurologia. Por exemplo, concluirá que é irremediável a desintegração da hegemonia mundial americana o relatório produzido por Samuel P. Hutington (1968). Isso não deixa de ser irônico, sabendo que, bem perto do ano 2000, o mesmo "politólogo" forjará a expressão "superpotência solitária" para designar a hegemonia absoluta da América (1999).

\section{Criar o desejo pela democracia interativa}

"Foram os Toffler que levaram o futuro às massas. O Choque do Futuro fez com que a profissão entrasse nos costumes de um modo legal. Esse bestseller e seus subprodutos, como $A$ Terceira Onda, fixaram a norma segundo a qual passaram a ser avaliados todos os futuristas seguintes." Esse é o balanço que fazia em 1996 um jornalista da revista Time a respeito da trajetória da "primeira geração de profissionais do prognóstico".

Primeira geração em relação à segunda, a dos anos 80 , comanda pelo visionário da web das webs e antigo quadro da Rand, Nicholas Negroponte, atualmente pesquisador do Laboratório de Mídia do MIT e colaborador da revista Wired (isso segundo o volume de citações do qual foi objeto desde 1994 pelo New York Times) (Krantz, 1996: 42).
Alvin Toffler lançou O Choque do Futuro em 1970. Nenhum dos títulos em voga servia então aos olhos desse antigo companheiro de rota do marxismo e consultor independente que trabalhava em colaboração com sua esposa, Heidi. Nenhuma deles lhe permitia dar conta das mudanças em curso. Destarte, ele substitui o termo "sociedade pós-industrial " e seus sucedâneos pelo termo "sociedade superindustrial", por meio da qual ele pretende significar uma "sociedade completa, de cadência muito rápida, que repousa sobre uma tecnologia extremamente avançada e um sistema de valores pós-materialista". A revolução superindustrial ratifica a falência do sistema industrial, que não é mais nem capitalista nem comunista, mas é, antes, a bancarrota da uniformização, da normalização e da centralização. Enterram-se as antigas ideologias rígidas e as velhas etiquetas de esquerda/direita, originárias do industrialismo. Rompem-se as instituições familiares e comunitárias. As velhas sociedades de massa se deslocam e se "desmassificam". Pelo ano 2000 vê-se uma sociedade diversificada, heterogênea, porque somente a diversidade pode permitir à humanidade sobreviver.

A mudança de margem dos processos sociais e políticos e a necessidade de se acomodar à nova sociedade, de assumir o choque do futuro, por parte da massa dos cidadãos, justificam a seus olhos uma "nova teoria da adaptação". Nessa, precisamente, entram em jogo os cenários do futuro que elaboram os profissionais do prognóstico. O sistema e as regulamentações políticas são incapazes de responder à precipitação do tempo e dos fluxos. Os cidadãos que carecem de recursos para medir as mudanças correm o risco de ser atingidos pelo "traumatismo do choque do futuro". Caso queiramos controlar a chegada da nova sociedade, é necessário um trabalho propedêutico de ingresso na era superindustrial. A missão da "estratégia da democracia prospectiva!" (antecipatory democracy) é permitir a todos os cidadãos comuns, e 
não apenas a um punhado de elites, assumir em suas próprias mãos o futuro. Para facilitar esse processo, é preciso dar aos cidadãos razões para esperá-lo, é preciso insuflar neles uma nova energia, baseada na exibição de imagens positivas da América superindustrial. Num segundo estágio, sempre tendo em vista o longo prazo, é preciso estudar - setor por setor - quais tecnologias deverão ser desencorajadas ou mesmo banidas, como desmembrar as macroinstituições, empresas, sindicatos, administrações, a fim de permitir a participação democrática, etc. Em terceiro lugar, a fim de realizar uma transição pacífica de uma sociedade a outra, é preciso ter uma idéia de planificação, tanto no nível nacional quanto transnacional. Pouco importa qual seja ela, desde que seja uma planificação de baixo para cima, uma planificação adaptada à "era da antiespecialidade". Para tanto, é preciso votar uma lei sobre a participação nacional e criar um instituto nacional de participação, que estudará os meios para implicar os cidadãos e colocar os novos meios tecnológicos de informação e de comunicação a sua disposição (voto eletrônico, comunicação interativa por meio de cabo). A democracia prospectiva obrigará certamente a uma revisão da Constituição, porque "nenhuma empresa procurará gerenciar seus negócios seguindo um quadro organizacional redigido a bico de pena há duzentos anos" (Toffler, 1976: 277).

Em A Terceira Onda (1979), Toffler retoma seus temas favoritos (desmassificação dos meios de comunicação, produção/consumo, mentalidades, descentralização, pluralismo, interatividade, fim da passividade, pleno emprego e flexibilidade) e os submete a uma perspectiva planetária. Sobrevoando a história, a civilização da terceira onda englobará a onda industrialista e suas filas de desempregados. Uma nova filosofia sobre a racionalidade técnica se travará no "supercombate pelo amanhã", que não passa mais pelas divisões de propriedade, da pobreza e da ideologia, mas pela linha entre antigos e modernos. As for- ças indomáveis do par novos valores/novas tecnologias transformarão o Estado-nação em um "perigoso anacronismo". Nascerá uma consciência cósmica, promovida pelos novos atores da economia mundial. Haverá uma economia que não será guiada nem pelo liberalismo, nem pelo marxismo, mas pelo "globalismo", isto é, "a idéia segundo a qual o nacionalismo viveu". O que emergirá não é um mundo onde as grandes corporações serão soberanas (Toffler pensa que essas grandes unidades se concentrarão menos sobre o lucro e mais sobre os problemas ecológicos, éticos, sociais e sexuais), nem um governo planetário, mas um sistema muito mais complicado, próximo das "organizações matriciais". Nos anos 90, os Toffler e sua sociedade multimídia FutureNet serão os pilares do cyberbrain trust do porta-voz da Câmara dos Deputados Newt Gingrich, feroz partidário de uma completa desregulamentação das redes.

\section{Geopolítica: • advento de um novo universo}

\section{A era tecnotrônica}

Desde o final dos anos 60, o referencial geopolítico que legitima a idéia de entrada na era da informação se encontra claramente explicitado nas análises de Zbigniew Brzezinski. Em primeiro lugar, em um artigo aparecido em janeiro de 1968 na revista Encounter, sob o titulo de "American in the Technetronic Age". Em seguida, na obra Between Two Ages: America's Role in the Technotronic Era, publicada em 1969. A tradução francesa da obra apareceu no ano seguinte na coleção "liberdade de Espírito", dirigida por Raymond Aron, com o título de $L a$ Révolution Technotronique. Por intermédio desse especialista em problemas do comunismo da Universidade de Columbia, a geopolítica passa a pensar a evolução do confronto entre os blocos sob o efeito da revolução tecnotrônica, um fruto da convergência tecnológica. A expressão "sociedade 
pós-industrial" e "aldeia global" não lhe pareciam muito aptas a exprimir a transição radical entre as "duas eras". Da mesma forma que a sociedade industrial não foi batizada de sociedade pós-agrícola, parecelhe que não é conveniente chamar de pósindustrial a sociedade do futuro. Quanto à noção de aldeia global, é refutada pelos fatos, na medida em que a nova realidade global não é um retorno à intimidade das pequenas comunidades, mas a imersão no anonimato das grandes megalópoles. Havendo-se de conservar uma imagem, seria a de "cidade global". Com Daniel Dell, o autor divide a idéia inquebrantável dos papéis da ciência e da universidade, destinadas a se tornarem um "reservatório de pensamentos, intensamente ligado à vida! E a assegurar a maior parte da planificação política e da inovação social" (Brzezinski, 1969: 31). A rede mundial de informação permite a reunião dos conhecimentos conducentes à formação de elites profissionais internacionalistas e o nascimento de uma linguagem científica comum, "funcionalmente equivalente ao latim".

O argumento central de Brzezinski é o seguinte: a unificação do mundo se acelerou singularmente, neutralizada que está pela expansão das redes de informação e de comunicação; essas últimas mudam a situação política das relações internacionais; o controle dos dispositivos de informação e cultura joga cada vez mais um papel estratégico na definição do "poderio mundial", na medida em que a "diplomacia das redes" está em via de substituir a "diplomacia do canhão"; o planeta vai, portanto, se tornar uma "sociedade global"; mas até agora o único país que, devido ao seu poder de irradiação, merece o nome de "sociedade global" são os Estados Unidos, porque ele "comunica-se mais do que qualquer outra sociedade" (mais de 65\% das comunicações passam por ele); e, devido a essa maturidade, a sociedade americana se tornou o farol que ilumina o caminho de outras nações.

Em termos políticos, isso quer dizer que, doravante, não podemos mais falar de "imperialismo cultural" americano em relação ao resto do mundo - tema que então mobiliza numerosas teorias e movimentos críticos em relação à sua hegemonia - porque suas indústrias culturais, seus modos e modelos de organização tornaram-se naturalmente universais; o que os Estados Unidos propõem é um modelo global de modernidade, esquemas de comportamento e valores passíveis de imitação por todo o planeta. A "sociedade global" será, portanto, a extrapolação de um arquétipo nascido e acabado do outro lado do Atlântico. Tais são as premissas a partir das quais se elabora uma "nova consciência planetária" que ultrapassa "as culturas firmemente enraizadas das religiões tradicionais solidamente entrincheiradas e as identidades nacionais bem distintas", e por meio da qual se afirma uma "nova unidade mundial que está em via de encontrar sua "própria estrutura, o consenso e a harmonia sobre as quais se apoiará" (Brzezinski, 1970: 87-91).

Pondo de lado as relações de força imperiais e naturalizadas, os modelos culturais da Pax Americana, Brzezinski se volta para a tese do fim da ideologia. De fato, seu livro pode ser lido como o coroamento em chave geopolítica de todos os discursos sobre os "fins" postos em circulação depois do Congresso de Milão. Note-se que um capítulo leva o título muito significativo de "Ideais e ideais além das ideologias". O leitmotiv reza que a revolução tecnotrônica torna caduca toda veleidade da revolução política.

Os pesquisadores da Universidade de Columbia acreditavam nela cegamente, chegando ao ponto de proclamar que, vistos os formidáveis progressos dos modernos meios de comunicação, "o problema que consiste em permitir que um conferencista seja entendido tanto pelos estudantes da Universidade de Columbia quanto os da Universidade de Teheran é apenas um problema de tempo (para ser resolvido)." Dez anos mais tarde, a Revolução dos Mulás derrubaria a ditadura do Xá e a nova 
república islâmica fechará as fronteiras ao "Grande Satã"!

\section{A religião da infosfera}

Por que situar aqui o pensador da videosfera Marshall McLuhan? De resto, sob a rubrica da geopolítica? Primeiramente porque ele é um dos primeiros a estabelecer uma ponte entre a videosfera e a infosfera no último capítulo de Os meios de comunicação como extensões do homem (Understanding Media, 1964). Em seguida porque Bell, Toffler, Brzezinski e outros inventores de neologismos sobre a sociedade do futuro se posicionaram em relação a sua fórmula de choque "aldeia global". Enfim, elemento fundamental, porque o professor de Toronto reconstrói uma visão religiosa da integração planetária, declinável em todas as etapas da era da informação, qualquer que seja a técnica. Através de sua intermediação, a teologia se torna culto das redes. Quanto a saber por que situamos McLuhan em relação à rubrica geopolítica, eis a razão: foi o primeiro aprendiz de feiticeiro do simbolismo tecnoglobalista.

Em sua primeira obra, The Mechanical Bride: Folklore of Industrial Man (1951), McLuhan adota a técnica de colocar em perspectiva crítica a cultura de massas que lhe foi ensinada por Frank R. Leavis, precursor dos estudos culturais britânicos e cujos cursos ele seguiu durante os três anos que passou no Trinity College (Cambridge, RU, 1935-1938). Adaptando a técnica clássica de explicação de textos à análise da publicidade americana, ele expõe os pressupostos de ordem social, econômica e política subjacentes aos anúncios. A novidade está em que, para desmascarar a publicidade, ele usa máscara e se vale da paródia.

Nos livros seguintes, A Galáxia de Gutenberg (1962) e Understanding Media (1964), McLuhan põe de lado a função crítica para se voltar contra a elite intelectual que, ao questionar o progresso industrial, se torna culpada de passadismo. Por uma dessas ironias que por vezes ocorrem na história, foi, pois, um especialista em literatura do período elizabetano e jacobita, autor de uma tese de doutorado sobre Thomas Nashe e antigo discípulo de um mestre desencantado com a cultura da mídia, que se incumbiu de fazer entrar as novas tecnologias de comunicação no universo mental do tecnicismo! Através de sua pena, as teses críticas sobre o industrialismo e as possibilidade de por meio da eletricidade recriar a comunidade do geógrafo anarquista Piotr Kropotkin e seus continuadores (Patrick Geddes e Lewis Mumford), em que visivelmente se inspira, são privadas de força corrosiva que havia lhes insuflado o pensamento utópico (Carey, 1981). Disso tudo resta apenas uma concha vazia com que procura preencher o determinismo tecnológico presente em Understanding Media:

"A eletricidade descentraliza, ao invés de centralizar. ... Vejamos a diferença entre uma rede ferroviária e uma rede de eletricidade. A primeira requer grandes aglomerações urbanas e fins de linha. A energia elétrica, disponível no campo tanto quanto no escritório de uma chefia empresarial, não requer aglomerações importantes e permite a qualquer um se tornar o centro" (McLuhan, 1993: 73-79).

Desaparecem os traços de um mundo marcado pelas injustiças sociais que obcecavam os pensadores da transição da era paleolítica para a época neotécnica. Em lugar e vez disso, há uma reconciliação indolor das antinomias de um mundo simbolizado pela "aldeia global".

O profetismo técnico aí existente tem sua fonte de inspiração teórica na história da igreja. McLuhan jamais cessou de repetir que o grande abalo que rompeu o corpo da comunicação e a desmembrou teve lugar na Idade Média. Se a Igreja perdeu posição nessa época, se ela aí perdeu sua unidade mística, foi por causa da tecnologia. A 
cultura medieval baseada sobre o manuscrito implodiu sob o impacto da revolução de Gutenberg. Essa baniu um estilo de vida comum em favor de uma comunidade massiva onde cada indivíduo pode se tornar um leitor e onde a leitura se torna uma experiência privada. Ora, a cultura do olhar que ela implodiu não é uma força unificadora mas fragmentária. Um dos aspectos inéditos da era da eletricidade é que nela se instaura uma "rede global", uma "interdependência global", que permite à "grande família humana" recriar o "estado compacto da vida aldeã" e por fim à "fragmentação". "A nova cultura elétrica fornece novamente base tribal a nossas vidas", observa, entrevendo a expressão "aldeia global", em A Galáxia de Gutenberg, livro que, na França, será publicado seis anos mais tarde por uma editora especializada na publicação de oratórios e obras religiosas.

McLuhan se converteu à religião católica aos 25 anos. Embora discreto no tocante a sua fé, jamais hesitou em confessá-la. “Tudo está no Evangelho: é preciso consultá-lo com freqüência", dizia ele em uma entrevista com Pierre Babin, ex-colega, religioso e pesquisador do Centro Nacional de Pesquisas Científicas (CNRS). “A fé de McLuhan é um todo indivisível que moldou e inspirou seu pensamento e sua existência", confirme Derrick de Kerkhove, diretor do programa Marsahll McLuhan da Universidade de Toronto (Kerkhove, 1990). $O$ inventor da aldeia global certamente não teria renegado a definição de transcendência comunicacional que deu Pierre Babin:

“A revelação da comunicação? Tratase da comunhão fraternal de todos os homens com Cristo. A prova dessa revelação? É a de podermos concretizar a unidade fundamental do gênero humano e corrigir todas as distorções da comunhão. Carregamos no coração o velho sonho da Santa Aliança, embora de modo diferente do que o foi na Idade Média" (Babin, 1985).

O promotor da aldeia global retoma as precoces intuições do teólogo jesuíta e paleontólogo Pierre Teilhard de Chardin (1881-1955), inventor da noção de "planetarização" ou "consideração global da humanidade", introduzidas em O fenômeno humano, escrito entre 1938-1940 e reelaborado em 1947/1948 (Chardin, 1955). Em A Galáxia de Gutenberg, McLuhan refere-se nada menos do que nove vezes a essa opus magna do pensador da "totalidade cósmica" e lança sua noção de aldeia global ao fazerlhe citação:

"Na medida em que, sob efeito dessa pressão e graças à sua permeabilidade psíquica, os elementos humanos reagem uns sobre os outros, seu espírito (por misteriosa coincidência) passa a se expandir e como que dilatado por si mesmo amplia todo o raio de sua zona de influência sobre a Terra. Através desse processo, porém, ele própria passa a encolher. Que vemos de fato se produzir no paroxismo moderno? Já o notamos várias vezes. Devido à descoberta, ontem, do caminho de ferro, do automóvel, do avião, a influência física de cada homem, reduzida a uns poucos quilômetros, se estende agora a centenas de lugares. Mais ainda: graças ao prodigioso evento biológico representado pelas ondas eletromagnéticas, cada indivíduo se encontra, doravante, (ativa e passivamente) presente ao mesmo tempo na totalidade dos mares e dos continentes - torna-se co-extensivo à Terra" ( McLuhan, 1977: 73-74).

Segundo Teilhard de Chardin: “Na atual hora, o cristianismo representa em toda a face da noosfera a única corrente de pensamento suficientemente audaciosa e progressista o bastante para abraçar todo o mundo num gesto indefinidamente perfeito, em que a fé e a esperança se consomem em caridade de maneira prática e eficaz" (Chardin, 1955: 299-300).

O entusiasmo de certos autores tecno- 
libertários desse princípio de século para com a visão escatológica do profeta da noosfera confirma, como se fosse preciso, sua perenidade.

\section{N Epílog॰}

\section{Rumo à sociedade da informação}

Em 1979, Bell adere formalmente à noção de "sociedade da informação":

"Cada sociedade é uma sociedade de informação e cada organização é um organismo de informação, assim como todo organismo é um organismo de informação. A informação é necessária para organizar e fazer funcionar qualquer coisa, da célula a General Motors" (Bell, 1979: 169).

A noção previa que essa situação seria válida para o Japão dentro de oito anos, data na qual o superministério da indústria e do comércio exterior (MITI), junto com os profetas da "sociedade multicentrada", escolheu a expressão "sociedade da informação" como objetivo nacional para o ano 2000. Em 1975, a OCDE, diante de três especialistas americanos, organizou em Paris a primeira reunião sobre as implicações do casamento de informações e das telecomunicações, no final da qual incorporou a noção de sociedade de informação à sua problemática sobre o crescimento. Quatro anos mais tarde, o conselho de ministros comerciais europeus fazia o mesmo ao decidir laçar um programa experimental qüinqüenal (Faz - Forecasting and Assessment in the Field of Science and Technology, Bjorn-Anderson et alli, 1982).

Em 1977, Marc Uri Porat, pesquisador em Stanford e um dos convidados de renome à reunião da OCDE, apresentou em primeira mão um relatório de nove volumes, que lhe havia encomendado o governo de Washington, sobre a "economia da informação" e seu alcance. A noção de socieda- de informação é aí descrita estatisticamente, ao mesmo tempo que o termo informação é definido como estoque numérico: "[informações] são quantidades de dados que foram organizados e comunicados" (Porat, 1977). Relativamente àquela que o economista americano Fritz Machlup havia feito quinze anos antes em seu estudo clássico sobre a extensão da "indústria do conhecimento" ("knowledge industry"), a noção de informação parece esvaziada de sua complexidade (Machlup, 1962). O dispositivo numérico de produção e de distribuição tende a se tornar o critério exclusivo de apreensão dessa nova mercadoria imaterial. A vontade política de legitimar a idéia de realidade aqui e agora, não só da economia da informação, mas da "sociedade de informação" verificada nos anos 70, foi, com razão, escrupulosa em termos de vigilância epistemológica. Conforme surgiam novas gerações de maquinas inteligentes, a tendência a confundir o sentido quantitativo com o sentido qualitativo, de assimilar a informação a um termo oriundo da estatística, se aprofundara. As sobreposições, confusões e equivalências entre informação, conhecimento, cultura e comunicação serão recorrentes, a despeito dos freqüentes alertas feitos por alguns matemáticos a respeito dos usos dessa "prótese semântica" (Thom, 1974). O encanto que cerca a noção de informação não cessará de envolver a de sociedade da informação.

\section{Os tempos de incerteza}

Antes mesmo de findarem os anos 70, rompe-se a visão linear da historia que inspira as várias especulações sobre o "arranque tecnológico". Levando em conta o sismo provocado pelo choque do petróleo, o relatório sobre a informatização da sociedade elaborado por Simon Nora e Alain Minc, a pedido do presidente (francês) Giscard D’Estaing (1978), rejeita a noção de crise e, ao mesmo tempo, uma filosofia terapêutica das redes. Há uma crise que, segundo os 
autores diagnosticam, toca de todo não só o modelo de crescimento mas também os mecanismos de construção da vontade geral. Em resumo, verifica-se uma "crise de civilização". No prólogo da edição de 1999 de $A$ sociedade pós-industrial, Bell não se deterá nesse aspecto do relatório, mas confirmará a importância que esse teve, assim como o projeto Minitel, na elaboração das representações americanas que dizem respeito à "autopista de informação para computadores e telecomunicações" (Bell, 1999, xxii). Notemos que Bell havia ele mesmo prefaciado a edição americana do relatório Nora-Minc, publicada em 1980 pelo MIT.

O relatório sobre o conhecimento que Jean-François Lyotard entrega ao Conselho das Universidades do Governo do Quebec reintroduz as asperezas de um sistema em que Bell via apenas evolução linear. A "comunidade carismática do conhecimento" deixa aí ver suas divisões. À diferença do sociólogo americano, totalmente crente na tecnociência, o filósofo trabalha com a hipótese de que o saber (e as instituições que o produzem) muda de estatuto ao mesmo tempo que "as sociedade ingressam na era pós-industrial e as culturas na era dita pósmoderna". A "condição pós-moderna" do saber é indiferente a respeito dos metarrelatos que a legitimam. A crise desses relatos que a época moderna inventou para sua auto-representação e para justificar ideologicamente a coesão social se confunde com a crise da filosofia da história como progresso. E essa crise intervém num momento onde o desafio maior do saber se tornou sua conversão em mercadoria e sua integração nas novas estratégias industriais e comerciais, militares e políticas. Um momento onde o critério de validação do saber que procura se impor é o da performance/performatividade, da eficiência mensurável em relação ao input/output, da linguagem da operatividade no sentido dos que decidem e do capital.

No curso dos anos 80, o simbolismo da era da informação será de qualquer modo posto de lado, senão eclipsado, pelo da globalização, secundado pela desregulamentação, para todavia voltar com força nos anos 90. O anúncio feito em 1994 pelo vice-presidente $\mathrm{Al}$ Gore do projeto de construir estradas de informação em escala planetária marcará a fusão desses dois universos, como atesta a circulação da noção de Global Society Information (Mattelart, 2000). Sinal disso, e que não nos deixa dúvida, é o fato de que nesse mesmo ano aparece pela primeira vez o conceito de New economy nos discursos oficiais •

\section{Nota}

* Artigo publicado originalmente como "L'Age de l'infor mation: Genese d'une appellation non contrôlée". Réseau 101 (pp. 21-48), 2000. Tradução de Francisco Rüdiger. Texto cedido à Revista FAMECOS pelo autor. 